\title{
Interaction of Phosphatidylserine-Phosphatidylcholine Liposomes with Sickle Erythrocytes
}

\author{
EVIDENCE FOR ALTERED MEMBRANE SURFACE PROPERTIES
}

\author{
Robert S. Schwartz, Nejat Düzgünes, Danny Tsun-Yee Chiu, \\ and Bertram Lubin, Bruce Lyon Memorial Research Laboratory, \\ Children's Hospital Medical Center, Oakland, California 94609
}

\begin{abstract}
A B S T R A C T The sickle erythrocyte (RBC) is a pathologic RBC that contains multiple membrane abnormalities. Some of these abnormalities have been implicated in the pathophysiology of vasoocclusive crises characteristic of sickle cell disease; others have yet to be defined in terms of their clinical significance. Recent information has shown that sickle RBC adhere abnormally to cultured endothelial cells yet little is known about the ways in which sickle cells interact with model membranes of defined size and lipid composition. We investigated this phenomenon by interacting sickle RBC with artificial lipid vesicles (liposomes) containing acidic phospholipids. Our results demonstrate that sickle disease (hemoglobin SS) RBC bind more of these liposomes than do normal or sickle trait (hemoglobin AS) RBC and that these differences are accentuated by hypoxia-induced sickling. Binding of liposome phospholipid to sickled RBC was not attributable to phospholipid exchange between liposomes and RBC and was consistent with a mechanism involving both membrane fusion and a stable reversible adhesion of liposomes to the RBC membrane.
\end{abstract}

Investigations into the mechanism(s) underlying increased liposome binding to sickled RBC suggested that the known reversible translocation of aminophospholipids, phosphatidylserine (PS) and phosphatidylethanolamine (PE), from the inner to the outer leaflet of the reversibly sickled RBC (RSC) plasma membrane during sickling may be a component of increased liposome binding to RSC. This idea was supported from results of experiments in which normal RBC were treated with diamide resulting in the expression of outer leaflet PE and PS and a stimulation of liposome binding to these cells. However, sickle RBC separated

Received for publication 9 July 1982 and in revised form 25 February 1983. according to cell density on stractan gradients showed that irreversibly sickled RBC (ISC) were less capable of liposome binding than were discoid RSC. Since ISC are known to contain elevated levels of outer leaflet aminophospholipids, such a result suggests that other changes in the plasma membrane of sickle cells, in addition to phospholipid reorganization, are probably involved in enhanced liposome binding to these cells. In other experiments, we showed that liposomes containing L-phenylalanine were capable of delivering this antisickling agent into intact sickle RBC as demonstrated by the partial inhibition of hypoxia-induced sickling in vitro. Our results suggest that liposomes can be used as sensitive probes for investigating changes in RBC membrane properties, especially those that affect intermembrane interactions, and that liposomal transport systems may have significant implications in the therapy of sickle cell disease.

\section{INTRODUCTION}

Although the primary lesion in the sickle erythrocyte $(\mathrm{RBC})^{1}$ is the presence in these cells of sickle hemoglobin $(\mathrm{Hb})$, many other components within the sickle RBC are also abnormal. Recent studies have shown that there are marked changes in the sickle RBC plasma membrane. For example, the phospholipid organization of the plasma membrane is altered in deoxygenated sickle RBC (1). Deoxygenation results in the

\footnotetext{
${ }^{1}$ Abbreviations used in this paper: BSKG, phosphate-buffered saline containing $5 \mathrm{mM}$ potassium and $11.1 \mathrm{mM}$ glucose; DPPC, labeled, L- $\alpha$-dipalmitoyl $\left[\right.$ methyl $-{ }^{14} \mathrm{C}$ or $\left.{ }^{3} \mathrm{H}\right]$ choline; $\mathrm{Hb}$, hemoglobin, Hct, hematocrit; ISC, irreversibly sickled RBC; PC, phosphatidylcholine; PE, phosphatidylethanolamine; PHE, L-phenylalanine; PLA 2 , phospholipase $A_{2}$; PS phosphatidylserine; RBC, erythrocyte; RSC, reversibly sickled RBC; WBC, leukocytes.
} 
accelerated transbilayer movement of phospholipids (2) leading to an increased exposure of the aminophospholipids phosphatidylserine (PS) and phosphatidylethanolamine (PE) on the external leaflet of the plasma membrane (1). In addition, the sickle RBC membrane has elevated levels of surface glycoproteins (3), membrane-bound calcium $(4,5)$ and $\mathrm{Hb}(6)$, abnormalities in the structure of the spectrin-actin cytoskeleton (7), and an increased susceptibility to lipid peroxidation (8). One possible result of such cumulative changes in the sickle RBC plasma membrane could be an altered interaction of sickle RBC with other cells. Indeed, Hoover et al. (9) and Hebbel et al. (10) have shown independently that sickle RBC were considerably more adherent to cultured endothelial cells than were normal RBC. Hebbel et al. (11) also demonstrated a strong correlation between sickle RBC adherence and clinical severity of disease. These workers found that oxygenated sickle RBC were more adherent than were deoxygenated sickle RBC, although many of the biochemical changes in the sickle RBC membrane are known to be exaggerated by hypoxia. They suggested that the RBC shape transformations accompanying hypoxia may render the sickled RBC less capable of adhesion in such an assay system. Here, we have investigated the interactions of liposomes with normal and sickle RBC to understand how sickling-induced changes in membrane surface properties affect intermembrane interactions. Liposomes, because of their relatively small size $(0.1 \mu \mathrm{m})$, might be expected to interact to a greater extent with the sickled RBC than would cultured cells, thus permitting a more detailed examination of the manifestations of changes in the sickle RBC membrane. We found that liposomes interacted to a much greater extent with the sickled RBC than with the discoid sickle or normal RBC. In addition, we were able to partially inhibit sickling in vitro by interacting sickle RBC with liposomes containing L-phenylalanine (PHE), indicating that liposomal contents had been effectively delivered into the sickle RBC cytoplasm.

\section{METHODS}

\section{Materials}

PS was prepared from bovine brain and phosphatidylcholine (PC) from egg yolk as described previously $(12,13)$, or purchased from Avanti Polar Lipids, Birmingham, AL. All lipids showed single spots when subjected to thin-layer chromatography using two different solvent systems (14). Lipids were stored under nitrogen in sealed ampules at $-50^{\circ} \mathrm{C}$. L- $\alpha$-Dipalmitoylphosphatidyl $\left[\right.$ methyl- ${ }^{14} \mathrm{C}$ or $\left.{ }^{3} \mathrm{H}\right]$ choline (DPPC), $\left[9,10-{ }^{3} \mathrm{H}(N)\right]$ triolein and $\left[\right.$ carboxyl $\left.-{ }^{14} \mathrm{C}\right]$ inulin were obtained from New England Nuclear, Boston, MA. Diamide (azodiacarboxylic acid bis[dimethylamide]) and PHE were from Sigma Chemical Co., St. Louis, MO. Stractan II was from St. Regis Paper Co., Tacoma, WA. AcquaMix aqueous liquid scintillation cocktail was obtained from WestChem, San Diego, CA. All other chemicals were reagent grade from standard sources.

\section{Procedures}

Preparation of vesicles. Large unilamellar vesicles (LUV) composed of PS/PC (3:1 molar ratio) were prepared by the reverse-phase evaporation technique (15), with some modifications (16). Radiolabeled DPPC or triolein were added in trace amounts $(0.21$ and $0.007 \%$ of total lipid, respectively) to the lipid mixture in chloroform. After the vesicles were formed they were uniformly sized to $0.1 \mu \mathrm{m}$ by extrusion through polycarbonate filters (Uni-Pore, Bio-Rad Laboratories, Richmond, CA) $(17,18)$. Vesicles containing encapsulated material ( $\left({ }^{14} \mathrm{C}\right]$ inulin or PHE) were separated from nonencapsulated material on a Sephadex G-75 $(1.5 \times 15 \mathrm{~cm})$ column (elution buffer: $20 \mathrm{mM}$ sodium Hepes, pH 7.4 containing $150 \mathrm{mM} \mathrm{NaCl}$ ). All vesicle preparations were centrifuged at $10,000 \mathrm{~g}$ for $30 \mathrm{~min}$ to separate multilamellar vesicles from LUV. Vesicles prepared by this method were stored under nitrogen at $4^{\circ} \mathrm{C}$ and were stable for at least 1 mo. The concentration of lipid in the various vesicle preparations was determined by standard procedures (19).

Sample preparation. After obtaining informed consent, fresh blood samples from patients with sickle cell disease $(\mathrm{Hb}$ $\mathrm{SS}$ ), sickle cell trait ( $\mathrm{Hb} \mathrm{AS}$ ), or from healthy normal controls (Hb AA) were collected in sodium heparin. Cells were separated from plasma by centrifugation (at $700 \mathrm{~g}$ for $10 \mathrm{~min}$ at $4^{\circ} \mathrm{C}$ ), leukocytes (WBC) were removed by aspiration of the buffy coat and the resulting $\mathrm{RBC}$ suspension was washed three times with $15 \mathrm{vol}$ of phosphate-buffered

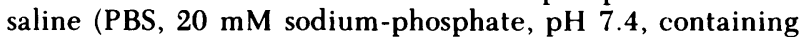
$150 \mathrm{mM} \mathrm{NaCl}$ ). Washed $\mathrm{RBC}$ were resuspended to $20 \%$ hematocrit (Hct) in PBS and cell counts ( $R B C$ and WBC) were obtained using the Coulter model $\mathrm{S}$ electronic cell counter (Coulter Electronics Inc., Hialeah, FL). WBC contamination generally represented $<1,000$ cells $/ \mu \mathrm{l}$ RBC suspension and was similar for normal, sickle-trait and sickle-disease RBC preparations. Deoxygenated RBC were prepared by incubating the RBC in a stoppered flask continuously flushed with humidified nitrogen for $1 \mathrm{~h}$ at $37^{\circ} \mathrm{C}$. Oxygenated $\mathrm{RBC}$ were incubated in room air. In some experiments, $\mathrm{RBC}$ were first induced to sickle by incubating them under nitrogen as above and then reoxygenated in room air ( $15 \mathrm{~min}$ ) until they returned to a biconcave shape. Samples of RBC following oxygenation or deoxygenation were fixed in PBS containing 2\% (final concentration) glutaraldehyde (in which oxygenated or deoxygenated conditions were maintained) and examined using light microscopy.

Liposome-RBC incubations. Oxygenated or deoxygenated RBC (4\% final Hct) were incubated with liposomes (10$1,000 \mu \mathrm{M}$ liposome phospholipid) in a total volume of 0.2 $\mathrm{ml}$ buffer $\mathrm{A}$ ( $20 \mathrm{mM}$ sodium-Hepes, $\mathrm{pH} 7.4$, containing 150 $\mathrm{mM} \mathrm{NaCl}$ ) at $37^{\circ} \mathrm{C}$ with constant gentle rotation for $1 \mathrm{~h}$, or as indicated. Oxygenated conditions were maintained by incubating under room air. Deoxygenated conditions were maintained by performing the incubations in sealed tubes $(12 \times 75 \mathrm{~mm})$ constantly flushed with humidified nitrogen. Buffers used for the deoxygenated experiments were equilibrated with nitrogen in sealed flasks for at least $1 \mathrm{~h}$ before their use. Liposome binding to RBC was measured by the residual uptake of radiolabeled liposomes following exhaustive washing of the RBC-liposome complex (three to four times, cells collected at $1,500 \mathrm{~g}$ for $5 \mathrm{~min}$ at $4^{\circ} \mathrm{C}$ ) with buffer 
A $(0.5 \mathrm{ml})$ or buffer A containing $6 \mathrm{mM}$ disodium EDTA, as indicated. Oxygenated RBC were washed with oxygenated (room air) buffer and deoxygenated RBC were washed with deoxygenated (nitrogen-flushed) buffer. Washed RBCliposome complexes were dissolved in $0.2 \mathrm{ml}$ of $1 \%$ sodium dodecyl sulfate containing $50 \mathrm{mM} \beta$-mercaptoethanol, followed by boiling for 1-2 min, the resulting lysate was decolorized by addition of $7 \%$ (final concentration) $\mathrm{H}_{2} \mathrm{O}_{2}$ and the mixture was allowed to stand overnight at room temperature. The decolorized solution was transferred to scintillation vials containing $10 \mathrm{ml}$ aqueous scintillation cocktail (AquaMix) for counting in a liquid scintillation spectrometer.

Cell separation. Blood $(40 \mathrm{ml})$ from normal and sickle cell patients was collected in heparinized tubes. RBC were separated from plasma by centrifugation $(1,000 \mathrm{~g}$ for $10 \mathrm{~min}$ at $4^{\circ} \mathrm{C}$ ), WBC were removed by aspiration of the buffy coat and the resultant RBC suspension was further washed (three times) with PBS containing $5 \mathrm{mM}$ potassium and $11.1 \mathrm{mM}$ glucose (BSKG). Washed RBC were resuspended to $20 \%$ Hct and layered on top of discontinuous gradients of Stractan II, prepared according to Corash et al. (20), as described by Clark et al. (21). Gradients were centrifuged for $30 \mathrm{~min}$ at $4^{\circ} \mathrm{C}$ in the Beckman SW 25.1 swinging bucket rotor (Beckman Instruments, Inc., Fullerton, CA) at 20,000 rpm in a Beckman model L8-80 ultracentrifuge. Separated RBC fractions (top (20\% stractan), middle (23\% stractan), bottom (26\% stractan)) were collected and washed (three times) with BSKG. Top and middle fractions of sickle blood contained $<2 \%$ irreversibly sickled cells (ISC) whereas bottom fractions contained $>70 \%$ ISC, as determined by light microscopy of representative samples fixed in $2 \%$ (final concentration) glutaraldehyde. Top fractions of normal and sickle blood contained $<8 \%$ and $>25 \%$ reticulocytes, respectively (as determined by methylene blue-stained smears). Middle and bottom fractions of both normal and sickle blood contained $<2 \%$ reticulocytes.

Treatment of RBC with diamide. Normal washed RBC were treated with the sulfhydryl-specific oxidizing agent diamide, as described by Haest et al. (22). RBC of $10 \%$ Het in isotonic phosphate buffer $(10 \mathrm{mM}$ sodium phosphate, $\mathrm{pH}$ 8.0 , containing $90 \mathrm{mM}$ potassium chloride, $45 \mathrm{mM}$ sodium chloride, and $44 \mathrm{mM}$ sucrose) were incubated with appropriate amounts of a stock solution of $100 \mathrm{mM}$ diamide to give a final diamide concentration of 1-5 mM. Incubations proceeded for $1 \mathrm{~h}$ at $37^{\circ} \mathrm{C}$ after which time the RBC were collected and washed (three times) with PBS. The diamidetreated RBC were allowed to stand for an additional $1 \mathrm{~h}$ at $37^{\circ} \mathrm{C}$ before use in the liposome-RBC interaction experiments or phospholipase $\mathrm{A}_{2}\left(\mathrm{PLA}_{2}\right)$ treatment. Phospholipid degradation using bee venom $\mathrm{PLA}_{2}$ was performed as described previously (1).

\section{RESULTS}

Liposome binding to RBC. Liposome binding to RBC could best be described by a rectangular hyperbola with a tendency to saturate at higher lipid concentrations (Fig. 1). Since the number of liposomes bound to normal RBC was found to be small ( $\sim 95$ liposomes/RBC at $100 \mu \mathrm{M}$ liposome lipid) we have used relatively high concentrations of liposome lipid $(100-1,000 \mu \mathrm{M})$ in all subsequent experiments. Liposome binding to $\mathrm{RBC}$ was linear with respect to the length of incubation (between 0 and $60 \mathrm{~min}$ at $37^{\circ} \mathrm{C}$ ) (Fig. 2) and to RBC Hct (between 2 and 10\% Hct, data not shown). The data plotted in Fig. 2 suggests that liposome binding is characterized by a very rapid initial uptake of liposomes (0-10 min) followed by a slower linear rate of uptake $(>10 \mathrm{~min})$. Such a result is consistent with liposome uptake by "high"- and "low"-affinity RBC-liposome binding sites.

When liposome binding was compared between normal and sickle $\mathrm{RBC}$, we found that oxygenated sickle RBC bound significantly more liposomes than did normal RBC (Fig. 3). When liposome binding was compared between deoxygenated and oxygenated sickle $\mathrm{RBC}$, it was apparent that the hypoxic sickle $\mathrm{RBC}$ were binding several times more liposomes than were the oxygenated sickle RBC (Fig. 3). Since both oxygenated and deoxygenated sickle $\mathrm{RBC}$ preparations were from the same blood donor and thus contained identical numbers of reticulocytes, it was apparent that the increased binding of liposomes to sickled RBC was due to some property related specifically to the sickled RBC and not to reticulocytosis per se. This was further demonstrated using sickle-trait (Hb AS) RBC (Fig. 4). The percentage of reticulocytes in sickle-trait blood is similar to that in normal blood (24) and indeed sickle-trait RBC do not normally sickle in vivo although they can be induced to sickle in vitro by incubating them under hypoxic conditions. Under such conditions, sickle-trait RBC bound significantly more liposomes than they did when oxygenated. However, the extent of liposome binding to the deoxygenated sickle-trait RBC was considerably less than that of deoxygenated sickle-disease ( $\mathrm{Hb} \mathrm{SS}$ ) RBC at comparable liposome concentrations.

Exchangeability of liposome and RBC glycerolipids. It is now well established that certain membrane glycerolipids may exchange between membranes both in the presence and absence of specific glycerolipid exchange proteins. Indeed, phospholipid exchange proteins have been used successfully to measure glycerolipid distribution and translocation in several biological membranes including those of $\operatorname{RBC}(25,26)$. To determine whether we were actually measuring true liposome binding to $\mathrm{RBC}$ or simply an artifact due to enhanced glycerolipid exchange between liposomes and $\mathrm{RBC}$, we compared the binding to normal and sickle $\mathrm{RBC}$ of liposomes labeled with $\left[{ }^{3} \mathrm{H}\right]$ triolein, a nonexchangeable glycerolipid (27) and liposomes labeled with [ $\left.{ }^{14} \mathrm{C}\right] \mathrm{DPPC}$, an exchangeable glycerolipid (28). We found that the extent of radiolabeled liposome uptake by RBC was similar using liposomes labeled with either marker (data not shown). Additional support against lipid exchange was obtained from experiments using liposomes with both a lipid marker 


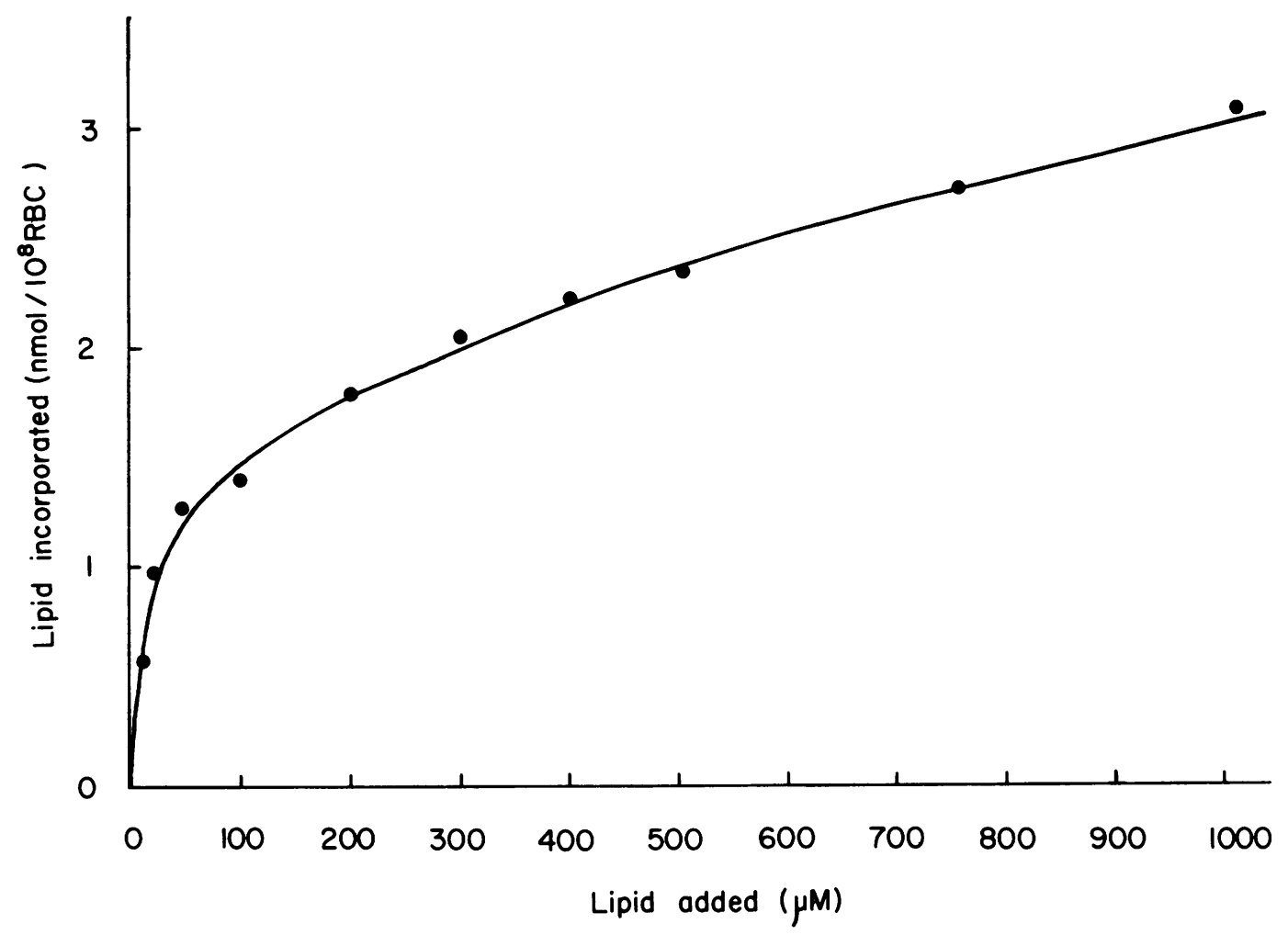

Figure 1 Incorporation of liposomes (PS/PC, 3:1, $0.1 \mu \mathrm{m}$ ) into RBC. Normal RBC (4\% Hct) were incubated with liposomes $(10-1,000 \mu \mathrm{M})$ labeled with $\left[{ }^{3} \mathrm{H}\right]$ triolein $(0.007 \%$ of liposome lipid) at $37^{\circ} \mathrm{C}$ in Hepes-buffered saline for $1 \mathrm{~h}$. Liposome incorporation was determined by measurement of residual RBC radioactivity following exhaustive washing of the liposome-RBC complex with PBS. RBC number was obtained using the Coulter model $S$ electronic cell counter. Data points represent the mean of at least three determinations.

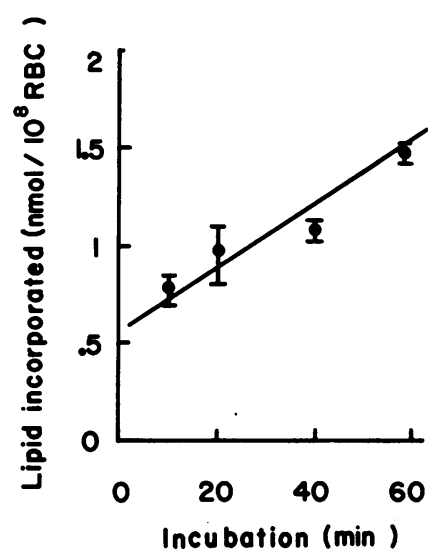

FIGURE 2 Incorporation of liposomes into RBC as a function of incubation time. Normal RBC were incubated with liposomes $(200 \mu \mathrm{M})$ at $37^{\circ} \mathrm{C}$ in Hepes-buffered saline for from 0 to $60 \mathrm{~min}$. Liposome composition, incorporation into RBC, and procedures for determining $R B C$ number were described in Fig. 1. Data points represent the mean \pm 1 SD of three determinations. $\left(\left[{ }^{14} \mathrm{C}\right] \mathrm{DPPC}\right)$ and an aqueous space marker $\left(\left[{ }^{14} \mathrm{C}\right] \mathrm{inulin}\right)$. $\mathrm{RBC}$ incubated with such double-labeled liposomes incorporated both lipid and aqueous space labels whereas RBC incubated with DPPC-labeled liposomes plus free radiolabeled inulin incorporated only radiolabeled DPPC (data not shown). We therefore feel that the mechanism of increased liposome binding to sickle RBC cannot be explained by an elevation in the rate of glycerolipid exchange between liposomes and sickle $\mathrm{RBC}$, but to some property directly attributable to the sickle RBC membrane that results in increased liposome-RBC interactions.

Liposome binding to diamide-treated RBC. Although our use of liposomes as a probe to examine surface properties of the sickle RBC was intended to generate information regarding cumulative changes in the sickle RBC membrane as a consequence of the sickling event, we were particularly interested in those changes relating specifically to phospholipid reorganization. The distribution of phospholipids within the membrane of sickled RBC is different from that in 


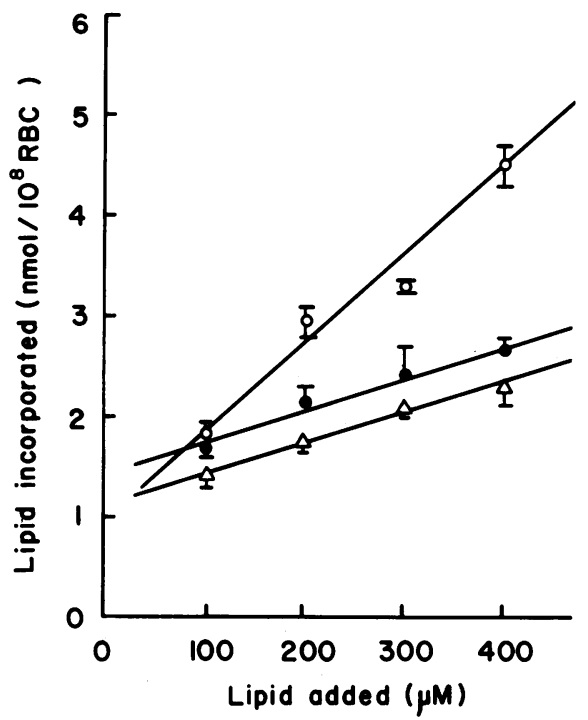

Figure 3 Incorporation of liposomes (100-400 $\mu \mathrm{M})$ into normal $(\Delta)$, oxygenated sickle $(\bullet)$, and deoxygenated sickle (O) RBC. Oxygenated RBC were preincubated at $37^{\circ} \mathrm{C}$ for $1 \mathrm{~h}$ under room air. Deoxygenated RBC were preincubated at $37^{\circ} \mathrm{C}$ for $1 \mathrm{~h}$ under humidified nitrogen. Liposome composition, incubation conditions, measurement of liposome incorporation and RBC number were described in Fig. 1. Deoxygenated normal RBC were also tested and liposome incorporation into these cells followed the same pattern as that for oxygenated normal RBC. Data points represent the mean $\pm 1 S D$ of at least three determinations.

nonsickled RBC. Compared with the nonsickled RBC, the outer leaflet of the sickled (hypoxic RSC or ISC) $\mathrm{RBC}$ is enriched in PE and contains PS while being depleted in PC (1). Since membranes containing PE and $P S$ are fusogenic in model membrane systems (30), we postulated that such phospholipid reorganization during sickling could be at least partially responsible for the observed increased binding of liposomes to sickled RBC. To test this hypothesis, we treated normal RBC with the sulfhydryl-specific oxidizing agent diamide (azodicarboxylic acid bis[dimethylamide]), which induces a loss of cytoskeletal integrity and results in the translocation of PE and PS from the inner to the outer leaflet of the RBC plasma membrane (22). As shown in Fig. 5, increasing the concentration of diamide exposed to normal RBC resulted in an increase in the amount of PE and PS on the outer leaflet of the membrane (panel A) while simultaneously stimulating the binding of liposomes to these RBC (panel B). Thus, liposome binding to diamide-treated $\mathrm{RBC}$ correlated well with the availability of PE and PS contained within the outer leaflet of the plasma membrane.

Liposome binding to density-separated RBC. Since sickle cell disease is characterized by reticulocytosis

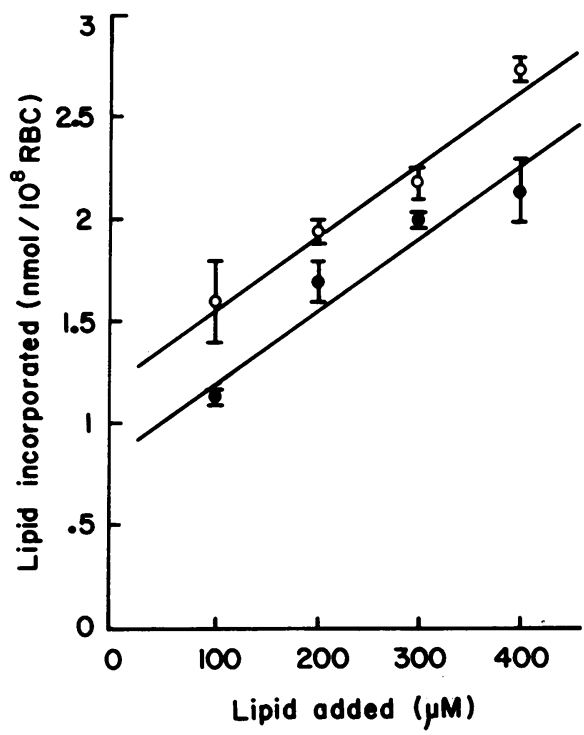

Figure 4 Incorporation of liposomes (100-400 $\mu \mathrm{M})$ into oxygenated (O) or deoxygenated $(O)$ sickle trait (Hb AS) RBC. Oxygenated RBC were preincubated at $37^{\circ} \mathrm{C}$ for $1 \mathrm{~h}$ in room air. Deoxygenated $\mathrm{RBC}$ were preincubated at $37^{\circ} \mathrm{C}$ for $1 \mathrm{~h}$ under humidified nitrogen. Liposome composition, incorporation into RBC, and measurement of cell number were described in Fig. 1. Data points represent the mean \pm 1 SD of three determinations.

(23), we could not exclude the possibility that increased liposome binding to sickle cells was due to enhanced binding to sickle reticulocytes. We therefore separated normal and sickle RBC into fractions according to cell density on Stractan II. We found that the top (least dense) fraction of sickle RBC, which was reticulocyte-rich but essentially devoid of ISC, bound the largest amount of liposomes (Table I). In contrast, normal RBC from the bottom (most dense) fraction bound the largest amount of liposomes. RBC from the middle fractions of both normal and sickle blood bound similar amounts of liposomes. For both normal and sickle cells, differences in RBC-liposome binding between density separated fractions could not be accounted for solely on the basis of differences in RBC surface area. For normal RBC, the difference in surface area of top vs. bottom fractions amounted to $<1 \%$ whereas for sickle $\mathrm{RBC}$ this difference was $\sim \mathbf{4 \%}$.

Role of divalent cations in the binding of liposomes to $R B C$. In model membrane systems, fusion or aggregation of PS- or PE-containing vesicles is divalent cation dependent $(29,30)$. We, therefore, investigated what effect divalent cations might be exerting on liposome binding to RBC. To test the hypothesis that the observed increased liposome binding to sickled RBC was due, in part, to a leakage of intracellular 

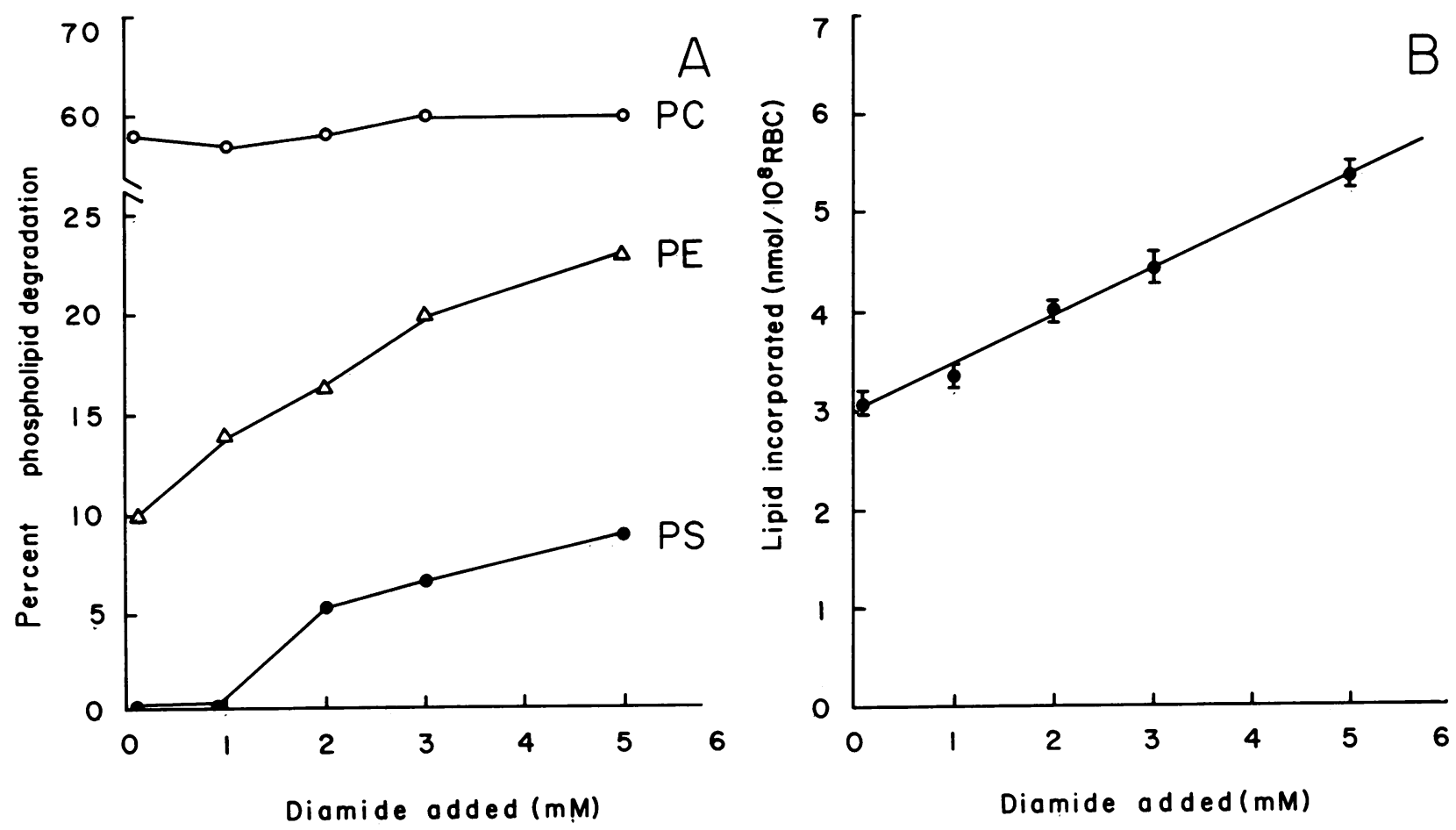

FIGURE 5 Liposome incorporation into diamide-treated RBC. Normal RBC (10\% Hct) were incubated with diamide $(1-5 \mathrm{mM})$ at $37^{\circ} \mathrm{C}$ for $1 \mathrm{~h}$ following which time the RBC were washed free of diamide. Treated $\mathrm{RBC}$ were allowed to stand at $37^{\circ} \mathrm{C}$ for an additional $\mathrm{l} \mathrm{h}$ before the addition of liposomes $(1 \mathrm{mM})$ or bee venom $\mathrm{PLA}_{2}$. Results are presented as the percentage of total lipid extractable RBC PS, PE, and PC degraded by PLA (panel A), and liposome incorporation into these cells (panel $B$ ) as a function of diamide concentration. Liposome composition, incorporation into RBC, and measurement of cell number were described in Fig. 1. Data points presented in panel $B$ represent the mean \pm 1 SD of three determinations.

divalent cations during RBC sickling, we performed the RBC-liposome incubations in the presence of the divalent cation-chelating agent EDTA. As shown in

TABLE I

Liposome Binding to Subpopulations of $R_{B C}{ }^{\circ}$

\begin{tabular}{llcc}
\hline Stractan fractiont & RBC sample & $n$ & Lipid incorporated \\
\hline \multirow{3}{*}{ Top } & & & $n m o l / 10^{8}$ RBC \\
& AA & 6 & $1.9 \pm 0.1$ \\
Middle & SS & 7 & $2.8 \pm 0.6$ \\
& AA & 5 & $1.9 \pm 0.1$ \\
Bottom & SS & 7 & $2.0 \pm 0.5$ \\
& AA & 3 & $4.0 \pm 0.6$ \\
& SS & 7 & $2.0 \pm 0.2$ \\
\hline
\end{tabular}

Values are mean $\pm 1 \mathrm{SD} ; \boldsymbol{n}$, number of determinations.

- $\mathrm{RBC}$ were incubated with liposomes $(200 \mu \mathrm{M})$ for $1 \mathrm{~h}$ at $37^{\circ} \mathrm{C}$.

$\ddagger$ Top and middle fractions of sickle RBC contain $<2 \%$ ISC. Bottom fraction of sickle RBC contain $>70 \%$ ISC.
Fig. 6, EDTA had no effect on liposome binding to normal or sickle(d) RBC. Furthermore, when oxygenated or deoxygenated RBC were first incubated with liposomes and then washed in EDTA-containing buffer, the extent of liposome binding was not altered (data not shown). Although such results suggest that liposome binding to sickled RBC is independent of the leakage of any intracellular divalent cations, they do not rule out the participation of membrane-associated divalent cations in the mechanism of liposome binding. It is possible that a pool of divalent cations are located within the RBC surface in such a way that they are inaccessible to EDTA yet can still participate in liposome-RBC interactions.

Reversibility of liposome binding. Since the reoxygenation of (reversibly) sickled RBC (RSC) results in the restoration of phospholipid asymmetry (1), we examined whether such a redistribution of membrane components causes the dissociation of liposomes that had adhered to (but not fused with) the sickled RBC membrane. As shown in Fig. 7, $\sim 25 \%$ of liposome 


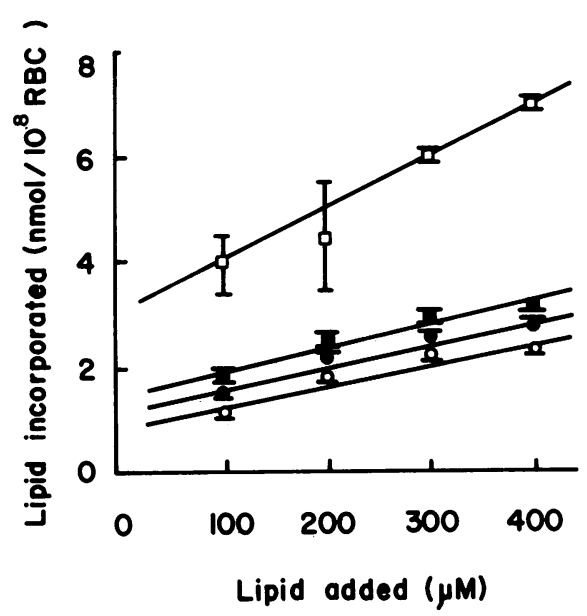

Figure 6 Effect of chelating agents on the incorporation of liposomes into sickle RBC. Normal (circles) or sickle (squares) RBC were incubated with liposomes $(100-400 \mu \mathrm{M})$ as in Fig. 3 except that the incubation mixture contained 6 $\mathrm{mM}$ disodium EDTA. The buffer used to wash the RBCliposome complex (following the incubation) also contained $6 \mathrm{mM}$ disodium EDTA. Oxygenated RBC (closed symbols) were preincubated at $37^{\circ} \mathrm{C}$ for $1 \mathrm{~h}$ in room air. Deoxygenated RBC (open symbols) were preincubated at $37^{\circ} \mathrm{C}$ for $1 \mathrm{~h}$ under humidified nitrogen. Liposome composition, incorporation into RBC, and measurement of cell number were described in Fig. 1. Data points represent the mean \pm 1 SD of three determinations.

radioactivity bound to the deoxygenated sickle $\mathrm{RBC}$ remained associated with the reoxygenated sickle $\mathrm{RBC}$, the remainder $(\sim 75 \%)$ being dissociated from the membrane during reoxygenation. These results suggest that liposome binding to sickled RBC involves both a reversible and a nonreversible component. We interpret the latter to be the result of nonreversible RBC-liposome fusion and the former as representing a reversible stable adhesion of liposomes to the $\mathrm{RBC}$ surface.

Inhibition of sickling using liposomes containing antisickling agents. In addition to using liposomes as probes for investigating erythrocyte membrane surface properties, a great deal of attention has focused, of late, on the use of liposomes as vehicles to deliver materials into cells (31). Since a large variety of agents that inhibit the gelation of sickle $\mathrm{Hb}$ in vitro have now been described $(32,33)$, but which are relatively impermeable to the RBC membrane, it was of interest to us to use liposomes as a transport system to deliver antisickling agents into the sickle RBC. For this purpose we prepared liposomes containing PHE, incubated these liposomes with sickle RBC and then deoxygenated the cells after having washed away unbound liposomes. As shown in Table II, sickle RBC exposed

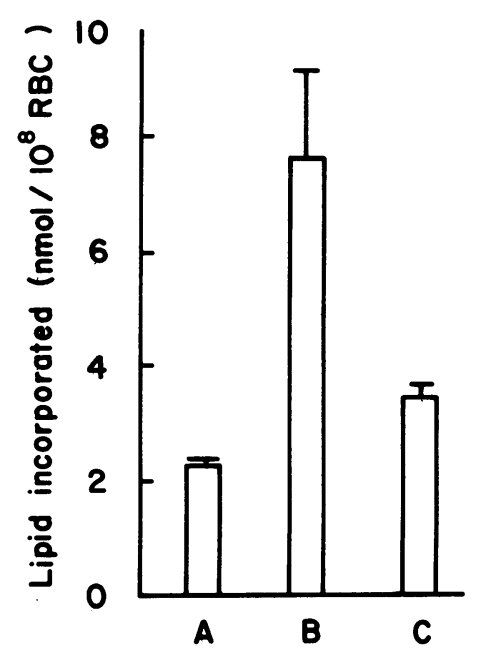

Figure 7 Effect of reoxygenation of deoxygenated sickle $\mathrm{RBC}$ on liposome incorporation. Liposomes $(200 \mu \mathrm{M})$ were incubated at $37^{\circ} \mathrm{C}$ for $1 \mathrm{~h}$ with oxygenated (A) or deoxygenated (B) sickle RBC following which time an aliquot of the deoxygenated cells were allowed to reoxygenate in room air for an additional $15 \mathrm{~min}(\mathrm{C})$. Oxygenated and the remainder of the deoxygenated $\mathrm{RBC}$ were also incubated for an additional $15 \mathrm{~min}$ so that all RBC were incubated with liposomes for a total of $75 \mathrm{~min}$. Oxygenated RBC were preincubated at $37^{\circ} \mathrm{C}$ for $1 \mathrm{~h}$ in room air while deoxygenated $\mathrm{RBC}$ were preincubated at $37^{\circ} \mathrm{C}$ for $1 \mathrm{~h}$ under humidified nitrogen. Liposome composition, incorporation into $\mathrm{RBC}$, and measurement of cell number were described in Fig. 1 . Values represent the mean $\pm 1 \mathrm{SD}$ of three determinations.

TABLE II

Inhibition of Sickling Using PHE-loaded Liposomes

\begin{tabular}{ccc}
\hline RBC treatment & Incubation & Percentage of sickle RBCt \\
\hline Liposomes (PHE) & $\min$ & \\
& 0 & 78 \\
& 30 & 63 \\
Liposomes + PHE & 60 & 40 \\
& 90 & 21 \\
& 0 & 70 \\
& 30 & 66 \\
& 60 & 75 \\
& 90 & 68 \\
\hline
\end{tabular}

- Oxygenated sickle RBC were incubated with liposomes (1 mM) containing $150 \mathrm{mM}$ PHE (liposomes [PHE]) or with liposomes + PHE for $1 \mathrm{~h}$ at $37^{\circ} \mathrm{C}$. The final concentration of PHE in the incubation mixture was $0.3 \mathrm{mM}$ for both treatments. Following the incubation, RBC were washed twice with PBS to remove unreacted liposomes and PHE, flushed with humidified nitrogen for $1 \mathrm{~h}$ at $37^{\circ} \mathrm{C}$, and then fixed by the addition of deoxygenated $3 \%$ (final concentration) glutaraldehyde.

I The results are presented as the percentage of RBC (mean of duplicate determinations), which when examined under light microscopy possessed a "maple-leaf" morphology typical of RSC. 
to PHE-loaded liposomes were significantly more resistant to sickling than were those $\mathrm{RBC}$ incubated with empty liposomes plus free PHE. Furthermore, the inhibition of sickling was dose dependent with regards to liposome-PHE concentration (data not shown). Not only do these results strongly suggest that liposomeRBC fusion had occurred, they also demonstrate a potentially valuable clinical application of liposomes in the therapy of sickle cell disease.

\section{DISCUSSION}

A large body of evidence has been gradually accumulating which demonstrates that the plasma membrane of the sickle $\mathrm{RBC}$ contains components that confer to this membrane unique surface properties. Although some of these properties have thus far been characterized only in the nonsickled (oxygenated) sickle RBC, most are known to be accentuated by hypoxia-induced sickling. Recently, much attention has focused on the clinical significance of these changes. For example, Chiu et al. (34) have shown that sickled $\mathrm{RBC}$ were capable of enhancing blood coagulation in vitro, presumably due to sickling-induced changes in the phospholipid distribution of the outer membrane leaflet that exposes PS. Hebbel et al. (10) and Hoover et al. (9) have shown independently that sickle RBC have a greater capacity for adhering to cultured endothelial cells than do normal RBC, and suggested that this increased adherence may be a pathologic factor in the microvascular occlusions characteristic of sickle cell disease. The purpose of the present report was to extend the observations regarding altered surface properties of the sickle RBC by using liposomes, which, because of their relatively small size $(0.1 \mu \mathrm{m})$ should be capable of extensive interactions with the RBC membrane. We felt that using liposomes in such a way might allow us to better characterize alterations in sickle cell intermembrane interactions, especially those that are accentuated by the sickling event and that might not be so apparent in other assay systems. We addressed the following questions: $(a)$ are there differences between normal and sickle RBC in the way these cells interact with liposomes? if so, $(b)$ what are the mechanisms involved in liposome sickle RBC interaction? and $(c)$ can these differences be exploited in a way to allow the use of liposomes as specific delivery systems for introducing potentially therapeutic compounds into pathological cells?

We found that sickle RBC interacted to a greater extent with liposomes than did normal cells and that these differences were accentuated by hypoxia-induced sickling. In this regard, liposome binding to sickle RBC could occur by one or a combination of several possible mechanisms: (a) adhesion of the liposome to the RBC surface, $(b)$ endocytosis of the liposome by the RBC, $(c)$ fusion of the liposome and RBC membrane, and/or (d) phospholipid exchange between liposomes and RBC. A priori, we excluded endocytosis as a reasonable mechanism since mature RBC are not known to be capable of spontaneous endocytosis under physiological conditions (35). Furthermore, ghosts prepared from sickle RBC (which are capable of drug-induced endocytosis) are less capable of ATP-induced endocytosis than are normal RBC (36).

We found that liposome-RBC adhesion occurred for both normal and sickle RBC. Hypoxic induction of sickling (in RSC) stimulated additional liposome binding to these cells. Of this increment, $\sim 25 \%$ we interpreted as representing liposome fusion, since that proportion of bound liposome was not reversible upon reoxygenation. Furthermore, we found that liposome binding to sickle cells could not be characterized as secondary to stimulation by intracellular divalent cation leakage during sickling. Thus, we propose that the sickling event results in some change(s) in the surface of the sickled RBC that exposes additional liposome binding sites, and that liposome binding occurs at least partially through liposome-RBC fusion. Increases in liposome binding to sickled RBC were apparent whether we used liposomes tagged with an exchangeable or a nonexchangeable lipid label, suggesting that phospholipid exchange between liposomes and sickle $\mathrm{RBC}$ was not occurring to any significant extent.

Extrapolation of the data presented in Fig. 3 to zero lipid added demonstrates significant base-line liposome incorporation for both normal and sickle RBC. From these results and those depicted in Fig. 2, which suggests the existence of distinct populations of "high"and "low"-affinity liposome binding sites, we speculate that observed differences in liposome binding to normal, oxygenated and deoxygenated sickle $\mathrm{RBC}$ reflects differences in liposome binding to the "low"-affinity liposome binding sites. At low liposome concentrations $(<100 \mu \mathrm{M})$ the number of liposomes bound per RBC is low ( $<100$ liposomes/RBC) and perhaps insufficient to saturate all of the "high"-affinity binding sites present on and similar for both normal and sickle RBC. At liposome concentrations $>100 \mu \mathrm{M}$, where differences in liposome binding between normal, oxygenated and deoxygenated sickle RBC were observed, we speculate that the "high"-affinity liposome binding sites are saturated. Therefore, that we did not detect differences in the extent of liposome binding between sickled and nonsickled cells at liposome concentrations $\leq 100 \mu \mathrm{M}$ suggests that our assay system was insensitive to differences in cell surface properties at this level. 
The nature of these additional liposome binding sites was examined by treating normal RBC with diamide, which causes membrane alterations including a reorganization of plasma membrane phospholipids resulting in the exposure on the outer leaflet of PS and additional PE (22). Such changes in membrane redistribution of PE and PS are similar to those found in deoxygenated RSC (1). We found that liposome binding to diamide-treated RBC increased as the availability of PS and PE on the outer leaflet of the bilayer increased. Thus, a strong correlation between the availability of outer leaflet aminophospholipids and liposome binding was established in these cells. It should be noted that while the percentages of outer leaflet PE and PS in diamide-treated RBC were similar to those previously reported for hypoxic sickle cells (1), liposome binding was substantially lower than would have been predicted for hypoxic sickle cells at similar liposome concentrations. Thus, although a qualitative relationship between phospholipid reorganization and liposome binding was established, these results also suggest that other, as yet unidentified components in the hypoxic sickle cell membrane, are contributing to enhanced liposome binding to these cells.

When liposome binding was examined in densityseparated RBC, we found that the extent of liposome binding to normal RBC was greatest in the bottom (most dense) fraction. In this regard, Schroit and collaborators ${ }^{2}$ have recently accumulated evidence which suggests that normal RBC enriched in PS (by incubation with PS liposomes) are phagocytized by cultured mouse or human macrophages to a greater extent than are nontreated, phosphatidic acid-enriched or PC-enriched RBC. These workers speculate that phospholipid redistribution in normal RBC may occur naturally as a consequence of cell aging and that exposure of PS on the outer leaflet of the membrane may enhance the recognition and phagocytosis of these cells by macrophages within the reticuloendothelial system. Our results also suggest that as normal RBC mature certain surface properties of these cells are altered in such a way as to confer to these cells a potential for increased intermembrane interactions.

In contrast to the results obtained for normal density-separated RBC, in sickle density-separated RBC the extent of liposome binding was greatest in the top (least dense) fraction. Since the bottom (most dense) fraction was enriched in ISC compared to the top fraction and ISC are known to contain elevated levels of outer leaflet aminophospholipids (expressed as a percentage of total ISC membrane phospholipid) (1), it

${ }^{2}$ Schroit, A. Personal communication. should follow that liposome binding to ISC would be enhanced if aminophospholipid redistribution were a component of the mechanism underlying increased liposome binding to hypoxic sickle RBC. That liposome binding to ISC was not increased suggests that aminophospholipid redistribution alone cannot explain enhanced liposome binding to hypoxic sickle cells. It should be mentioned that ISC are known to be different from RSC in several respects, which may affect their ability to interact extensively with liposomes. For example, ISC are considerably smaller and contain less total membrane lipid than do RSC (21). In addition, ISC demonstrate abnormal rheological properties (37) and contain irreversible cytoskeletal defects (7). Such cumulative membrane defects may contribute to the observed low levels of liposome binding to these cells.

That hypoxic Hb AS RBC bound fewer liposomes than did hypoxic Hb SS RBC at similar liposome concentrations similarly suggests that liposome binding can be affected by membrane components other than the content of outer leaflet PE and PS, which is similar for both cells (1). We speculate that in this case, differences in liposome binding may be related to alterations in the surface glycoprotein architecture of the Hb SS RBC membrane. In this regard, Fukuda et al. (3), have demonstrated that Hb SS RBC have a higher content of both $\mathrm{i}$ - and I-antigens. In addition, these workers found that following treatment with endo$\beta$-galactosidase, $\mathrm{Hb}$ SS RBC released considerably more sialic acid than did normal or nonsickle high reticulocyte $\mathrm{RBC}$. In related experiments, Hebbel et al. (10) demonstrated by electron microscopy that $\mathrm{Hb}$ SS RBC possess aberrations in surface charge distribution presumably representing alterations in the surface distribution of sialic acid. Thus, we speculate that the mechanism underlying increased liposome binding to $\mathrm{Hb}$ SS RBC involves both cooperative interactions between permanent alterations in sickle RBC membrane glycoprotein architecture and distribution of surface charges, with transient alterations in the content and distribution of outer leaflet aminophospholipids.

One possible application for the increased binding of liposomes by sickled RBC may be in developing new methods for the clinical treatment of sickle cell disease. For example, liposomes containing antisickling agents could be used to deliver intracellularly agents that cannot penetrate the RBC membrane. Indeed, we have been able to partially inhibit sickling in vitro using liposomes containing PHE. These results not only strongly suggest that liposome-RBC fusion had occurred, but point to the practical aspects of using liposomes in the therapy of sickle cell disease. It is also apparent from these studies that liposomes can be used 
as sensitive probes for investigating changes in the surface properties of cell plasma membranes. Furthermore, by changing the lipid composition and size of the liposome or by incorporating components such as proteins or glycoproteins into the liposome membrane, one can obtain further information regarding the interaction of altered erythrocyte membranes with model membranes of defined size and composition.

\section{ACKNOWLEDGMENTS}

The authors are grateful to Ms. Klara Kleman who performed the stractan gradient cell separations and sickle cell microscopy and to Mrs. Marion A. Douglass for her expert assistance in the preparation of this manuscript.

This work was supported by March of Dimes grant 1-768 and National Institutes of Health grants HL-20985 and HL27059.

\section{REFERENCES}

1. Lubin, B., D. Chiu, J. Bastacky, B. Roelofsen, and L. L. M. Van Deenen. 1981. Abnormalities in membrane phospholipid organization in sickled erythrocytes. J. Clin. Invest. 67: 1643-1649.

2. Franck, P., D. Chiu, B. Roelofsen, J. Op den Kamp, and B. Lubin. 1982. Accelerated transbilayer movement of phosphatidylcholine in sickled erythrocytes. Blood. 60(Suppl. 1): 45a. (Abstr.)

3. Fukuda, M., M. N. Fukuda, S. Hakomori, and T. Papayannopoulou. 1981. Anomalous cell surface structure of sickle cell anemia erythrocytes as demonstrated by cell surface labeling and endo- $\beta$-galactosidase treatment. J. Supramol. Struct. Cell. Biochem. 17: 289-297.

4. Eaton, J. W., T. D. Skelton, H. S. Swofford, C. E. Kolpin, and H. S. Jacob. 1973. Elevated erythrocyte calcium in sickle cell disease. Nature (Lond.). 246: 105-106.

5. Palek, J. 1977. Red cell calcium content and transmembrane calcium movements in sickle cell anemia. J. Lab. Clin. Med. 89: 1365-1374.

6. Asakura, T., K. Minakaza, K. Adachi, M. O. Russel, and E. Schwartz. 1977. Denatured hemoglobin in sickle erythrocytes. J. Clin. Invest. 59: 633-640.

7. Lux, S. E., K. M. John, and J. Karnovsky. 1976. Irreversible deformation of the spectrin-actin lattice in irreversibly sickled cells. J. Clin. Invest. 58: 955-962.

8. Lubin, B., and D. Chiu. 1980. Abnormal susceptibility of sickle erythrocytes to lipid peroxidation. In Red Blood Cells and Lens Metabolism. S. Srivastava, editor. Elsevier-North Holland, Inc., New York. 159-162.

9. Hoover, R., R. Rubin, G. Wise, and R. Warren. 1979. Adhesion of normal and sickle erythrocytes to endothelial monolayer cultures. Blood. 54: 872-876.

10. Hebbel, R. P., O. Yamuda, C. F. Moldow, H. S. Jacob, J. G. White, and J. W. Eaton. 1980. Abnormal adherence of sickle erythrocytes to cultured vascular endothelium: possible mechanism for microvascular occlusion in sickle cell disease. J. Clin. Invest. 65: 154-160.

11. Hebbel, R. P., M. A. B. Boogaerts, J. W. Eaton, and M. H. Steinberg. 1980. Erythrocyte adherence to endothelium in sickle cell anemia: a possible determinant of disease severity. N. Engl. J. Med. 302: 992-995.
12. Papahadjopoulos, D., W. J. Vail, C. Newton, S. Nir, K. Jacobson, G. Poste, and R. Lazo. 1977. Studies on membrane fusion. III. The role of calcium-induced phase changes. Biochim. Biophys. Acta. 465: 579-598.

13. Papahadjopoulos, D., and N. Miller. 1967. Phospholipid model membranes I. Structural characteristics of hydrated liquid crystals. Biochim. Biophys. Acta. 135: 624638.

14. Düzgüneş, N., J. Wilschut, R. Fraley, and D. Papahadjopoulos. 1981. Studies on the mechanism of membrane fusion: role of head-group composition in calcium- and magnesium-induced fusion of mixed phospholipid vesicles. Biochim. Biophys. Acta. 642: 182-195.

15. Szoka, F., and D. Papahadjopoulos. 1978. Procedure for preparation of liposomes with large internal aqueous space and high capture by reverse-phase evaporation. Proc. Natl. Acad. Sci. USA. 75: 4194-4198.

16. Wilschut, J., N. Duzguneş, R. Fraley, and D. Papahadjopoulos. 1980. Studies on the mechanism of membrane fusion: Kinetics of calcium ion-induced fusion of phosphatidylserine vesicles followed by a new assay for mixing of aqueous vesicle contents. Biochemistry. 19: 60116021 .

17. Olson, F., C. A. Hunt, F. C. Szoka, W. J. Vail, and D. Papahadjopoulos. 1979. Preparation of liposomes of defined size distribution by extrusion through polycarbonate membranes. Biochim. Biophys. Acta. 557: 9-23.

18. Szoka, F., F. Olson, T. Heath, W. Vail, E. Mayhew, and D. Papahadjopoulos. 1980. Preparation of unilamellar liposomes of intermediate size (0.1-0.2 $\mu \mathrm{m})$ by a combination of reverse phase evaporation and extrusion through polycarbonate membranes. Biochim. Biophys. Acta. 601: 559-571.

19. Bartlett, G. R. 1959. Phosphorus assay in column chromatography. J. Biol. Chem. 234: 466-468.

20. Corash, L. M., S. Piomelli, H. C. Cohen, C. Seaman, and E. Gross. 1974. Separation of erythrocytes according to age on a simplified density gradient. J. Lab. Clin. Med. 84: $147-151$.

21. Clark, M. R., R. C. Unger, and S. B. Shohet. 1978. Monovalent cation composition and ATP and lipid content of irreversibly sickled cells. Blood. 51: 1169-1178.

22. Haest, C. W. M., G. Plasa, D. Kamp, and B. Deuticke. 1978. Spectrin as a stabilizer of the phospholipid asymmetry in the human erythrocyte membrane. Biochim. Biophys. Acta. 509: 21-32.

23. Bensinger, T. A., and P. N. Gillette. 1974. Hemolysis in sickle cell disease. Arch. Intern. Med. 133: 624-631.

24. Chiu, D., B. Lubin, and S. Shohet. 1979. Erythrocyte membrane lipid reorganization during the sickling process. Br. J. Haematol. 41: 223-234.

25. Zilversmit, D. B., and M. E. Hughes. 1976. Phospholipid exchange between membranes. Methods Membr. Biol. 7: 211-259.

26. Crain, R. C., and D. B. Zilversmit. 1980. Two nonspecific phospholipid exchange proteins from beef liver. 2 . Use in studying the asymmetry and transbilayer movement of phosphatidylcholine, phosphatidylethanolamine, and sphingomyelin in intact rat erythrocytes. Biochemistry. 19: 1440-1447.

27. Enholm, C., and D. B. Zilversmit. 1973. Exchange of various phospholipids and of cholesterol between liposomes in the presence of highly purified exchange protein. J. Biol. Chem. 248: 1719-1724.

28. Struck, D., and R. Pagano. 1980. Insertion of fluorescent 
phospholipids into the plasma membrane of a mammalian cell. J. Biol. Chem. 255: 5404-5410.

29. Düzgünes, N., K. Hong, and D. Papahadjopoulos. 1980. Membrane fusion: the involvement of phospholipids, proteins and calcium binding. In Calcium Binding Proteins: Structure and Function. F. L. Siegel, E. Carafoli, R. H. Krestinger, D. H. MacLennan, and R. H. Wasserman, editors. Elsevier-North Holland, Inc., New York. 17-22.

30. Papahadjopoulos, D., G. Poste, and W. J. Vail. 1979. Studies on membrane fusion with natural and model membranes. Methods Membr. Biol. 10: 1-121.

31. Papahadjopoulos, D., editor. 1978. Liposomes and their uses in biology and medicine. Ann. N.Y. Acad. Sci. 308: 226-425.

32. Dean, J. D., and A. N. Schechter. 1978. Sickle-cell anemia: molecular and cellular bases of therapeutic approaches. N. Engl. J. Med. 299: 752-870.
33. Noguchi, C. T., and A. N. Schechter. 1978. Inhibition of sickle hemoglobin gelation by amino acids and related compounds. Biochemistry. 17: 5455-5459.

34. Chiu, D., B. Lubin, B. Roelofsen, and L. L. M. van Deenen. 1981. Sickled erythrocytes accelerate clotting in vitro: an effect of abnormal membrane lipid asymmetry. Blood. 58: 398-401.

35. Schekman, R., and S. J. Singer. 1976. Clustering of membrane receptors can be induced in mature erythrocytes of neonatal but not adult humans. Proc. Natl. Acad. Sci. USA. 73: 4075-4079.

36. Schrier, S. L., and K. G. Bensch. 1976. Endocytosis in resealed human erythrocyte ghosts: abnormalities in sickle cell anemia. In Membranes and Disease. L. Bolis, J. F. Hoffman, and A. Leaf, editors. Raven Press, New York. 31-40.

37. Chien, S., S. Usami, and J. F. Bertles. 1970. Abnormal rheology of oxygenated blood in sickle cell anemia. $J$. Clin. Invest. 49: 623-634. 